\title{
Mediastinal tumour with rare histology: case report
}

\author{
Ilaria Ceccarelli ${ }^{1}$, Stylianos Korasidis ${ }^{1}$, Elisa Sicolo ${ }^{1}$, Agnese Nesti ${ }^{1}$, Marcello Carlo Ambrogi ${ }^{1}$, \\ Piero Paladini' ${ }^{2}$, Marco Lucchi ${ }^{1}$
}

${ }^{1}$ Division of Thoracic Surgery, Department of Surgical, Medical, Molecular, Pathology and Critical Care, University Hospital of Pisa, Pisa, Italy; ${ }^{2}$ Thoracic Surgery Unit, University of Siena, Siena, Italy

Correspondence to: Dr. Ilaria Ceccarelli. Resident of Thoracic Surgery, Department of Surgical, Medical, Molecular, Pathology and Critical Care, University Hospital of Pisa, via Paradisa 2, 56124 Pisa, Italy. Email: i.ceccarelli19@gmail.com.

\begin{abstract}
Solitary fibrous tumour (SFT) of the pleura is a rare mesenchymal neoplasm usually originating from the parietal pleura or from the visceral pleura close to the fissures, but seldom can affect any anatomic site. Nowadays this kind of tumour is classificated, under a histological point of view, together with the hemangiopericytoma. Herein we report a case of a rare form of a bulky mediastinal SFT/ hemangiopericytoma ( heart and major mediastinal vessels, in a 67 years old female patient with a synchronous papillary thyroid carcinoma. The patient presented respiratory and cardiac symptoms due to the mass effect. Median sternotomy was mandatory because of the size and because of the suspected involvement of the inferior part of sternum body, as the CT images suggested. During surgery the mass result easily resectable from mediastinal structures with a confined, highly vascularized, implant base at the posterior wall of the sternal body. Final pathological report confirmed the presence of STF/hemangiopericytoma on the bone. During the immediate postoperative period were verified two episodes of atrial fibrillation, totally asymptomatic, converted with intravenous drug amiodarone with subsequent maintenance of sinus rhythm. In consideration of the location, the intraoperative features and the apparent origin from the capillary pericytic cell of the sternal periosteum, this tumour seems closer to a hemangiopericytoma histology than to a SFT, representing a rare localization for this kind of neoplasm. As well as for the SFT, also the histological features of this Hemangiopericytoma, direct to a "low malignant potential" and for this reason, a multidisciplinary group have decided for a radiological Follow up.
\end{abstract}

Keywords: Mediastinum; hemangioperictytoma; solitary fibrous tumour of the pleura (SFT of the pleura); sternum; soft tissue tumors; case report

Received: 03 November 2019; Accepted: 13 January 2020; Published: 25 February 2021.

doi: $10.21037 /$ ccts.2020.01.05

View this article at: http://dx.doi.org/10.21037/ccts.2020.01.05

\section{Introduction}

Pleural solitary fibrous tumour (SFT) is a rare mesenchymal neoplasm, representing less than $5 \%$ of all pleural tumours $(1,2)$.

Pleural smooth muscle tumors (SMTs) are not reported to be associated with exposure to asbestos fibres or tobacco smoking. In addition, this kind of tumour is usually solid, composed of well-circumscribed isolated lesion located at the periphery of the chest or closed to the fissure; latest studies show that occasionally, SMT can affect any anatomic site (3).
This neoplasm has always been characterized by pattern less proliferation of spindly tumour cells associated with pleomorphic cellule types.

SMTs are nowadays associated, under an histologic and immunohistochemical point of view with another kind of soft tissue neoplasm: hemangiopericytoma $(4,5)$.

A hemangiopericytoma is a sarcoma that presumably derived from ubiquitous capillary pericytic cell; it could be founded in every part of the body but usually it's more common in the extremities, meninges or retroperitoneum (5).

The common diagnosis SFT/hemangiopericytoma, 


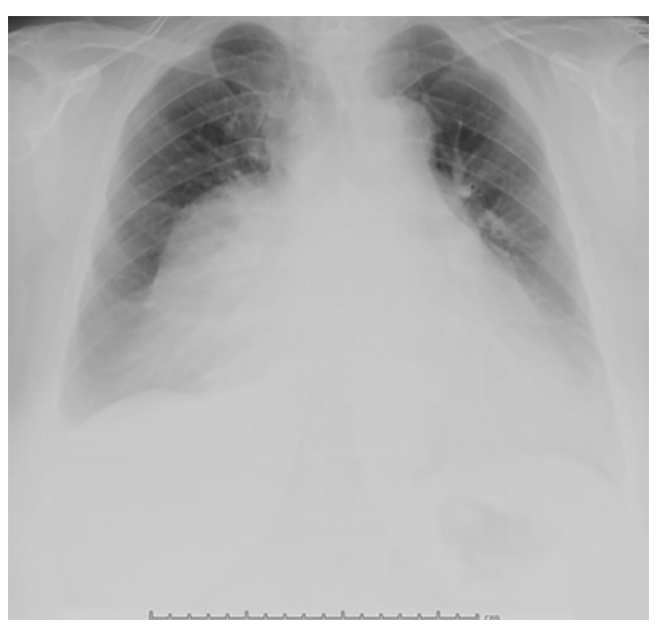

Figure $1 \mathrm{X}$-ray chest, pre-operative.

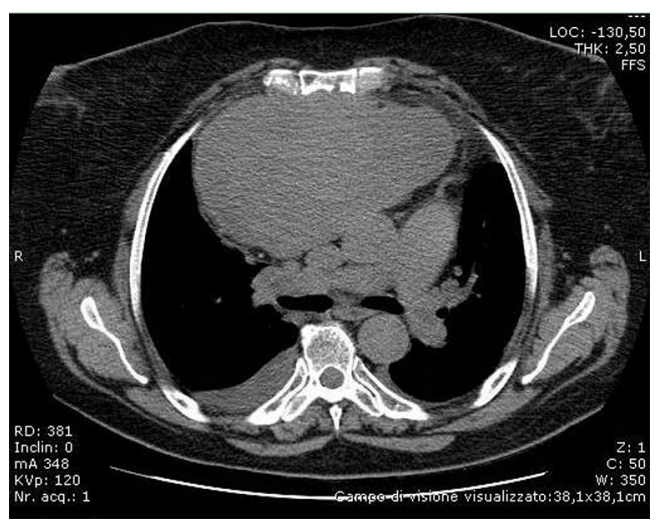

Figure 2 CT scan, pre-operative.

endorsed by the World Health Organization, is based on overlapping features. This includes CD 34 immunoreactivity, cytogenetic abnormalities, pathologic and clinical features: slow growth, clinical indolent until reaching relevant dimension, high local recurrence rate but non-aggressive behaviour (metastases rate is estimated to be less than $10-15 \%)(5,6)$. Nevertheless, there are some parameters that could allow to distinguish between these two types of tumour.

In this case report we are going to describe a particular type of SFT/hemangiopericytoma localized in the mediastinum. This neoplasm seems to originate from the capillaries of the sternum. We present the following case in accordance with the CARE reporting checklist (available at https://ccts.amegroups.com/article/view/10.21037/ ccts.2020.01.05/rc).

\section{Case presentation}

A 67-year-old woman, non-smoking, with negative anamnesis for neoplastic or cardiovascular disease, was reported episodes of palpitations and irregular heart rhythm from some months before the first medical interview. Additionally, she reported increased dyspnoea.

Because of a persisting flu symptom (5 months to the recovery), she underwent a chest $\mathrm{X}$-ray, that showed a well circumscribed semi-circular mass, which disfigured the cardiac profile on right side of the hemithorax (Figure 1).

Contrast-enhanced computer tomography scan of the chest confirmed the presence of a large mass in the anterior mediastinum $(15 \mathrm{~cm} \times 12 \mathrm{~cm} \times 9 \mathrm{~cm}$ in size $)$, solid and very close to the great vessels, particularly to the superior cava, innominate vein, ascending aorta and pericardium. The mass seemed to be closely interconnected to the sternum by its lower posterior face. Moreover, a multinodular thyroid goiter partially immersed in the mediastinum was identified (Figure 2).

First of all, laboratory investigation for thyroid was found to be within normal range.

Further serological tests, in order to identify the nature of the mass, were needed.

Taking into account the most common neoplasm with this size and this morphological features sited in the mediastinum we used alpha fetoprotein hypothesizing an embryonic origin; antibodies anti-acetylcholine receptor (AChr) were dosed in order to exclude a thymoma, potentially related to an asymptomatic Myasthenia Gravis. All these markers resulted to be negative.

Considering symptomatology, the size and the unknown aetiology and after a multidisciplinary evaluation the patient was candidate for the surgery.

All procedures performed in this study were in accordance with the ethical standards of the institutional and national research committees and with the Helsinki Declaration (as revised in 2013). Written informed consent was obtained from the patient for publication of this case report and any accompanying images. A copy of the written consent is available for review by the editorial office of this journal.

\section{Discussion}

Initially endocrine surgeons performed a thyroidectomy by cervicotomy with the Kocher technique.

Afterwards a median sternotomy was mandatory for 
approaching the mediastinal mass because of the size and due to the doubt involvement of the inferior part of sternum body, as suggested by the CT images.

During the sternotomy we experienced a moderate bleeding of the mass because of the injury of the part of the tumor infiltrating the low part of the body sternum. The mass was extremely voluminous and richly vascularized.

After controlling the bleeding, the lesion was successfully removed, through dissection and coagulation maneuvers.

After the total resection of the mass, a biopsy of the sternal margin was performed (Figure 3).

On the second post-operative day, the patient presented a first episode of atrial fibrillation. It has been treated with intravenous cordarone and proceeded with oral therapy.

A recurrence of fibrillation was recorded in third postoperative day with medical conversion. In both cases the patient presented no symptoms.

Considering this arrhythmia, the patient underwent

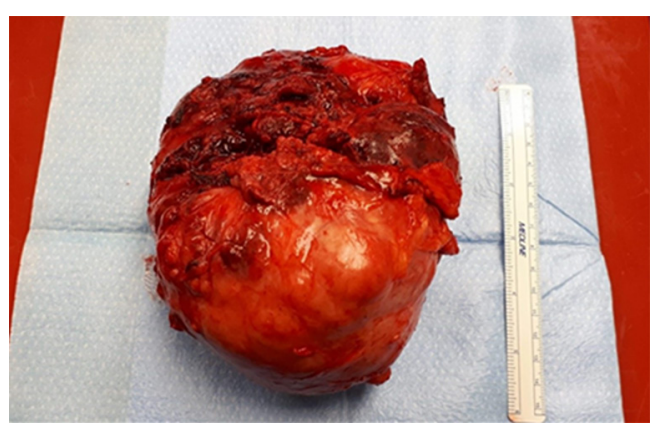

Figure 3 Tumor after surgical resection. cardiological examination. In view of mute cardiological history, normal ultrasound images, the cardiologist attributed the arrhythmic event to relocation of heart inside mediastinum after the resection of the large neoplastic mass.

The subsequent hospital stay proceeded without complications.

The patient was monitored using $\mathrm{X}$-ray chest that highlighted a moderate right pleural effusion. The patient was discharged on the tenth post-operative day.

The Histological report confirmed an STF/ hemangiopericytoma, sized $15 \mathrm{~cm} \times 12 \mathrm{~cm} \times 9 \mathrm{~cm}$. The immunohistochemical investigation showed a typical benign pattern and no increased mitotic activity was seen $(<5 \%)$. On the other hand, the biopsy of the sternal margin confirmed also microscopic presence of the STF/ Hemangiopericytoma cells (R1).

Despite the classification unites these two mesenchymal neoplasms, the mass in exam present some particular features.

First of all, the localization in anterior mediastinum was more typical of other kind of tumours like thymomas, embryonic neoplasms or lymphomas, than STF.

Secondly, the involvement of the sternum. The mass seemed to originate directly from the capillary pericytic cell of the sternum; rich vascularization of the mass and its continuity with the sternum, histologically confirmed, are both aspects confirming this classification.

In consideration of the location, the intraoperative features and the likely origin from the capillary pericytic cell of the sternum, this case could be a tumour closer to the
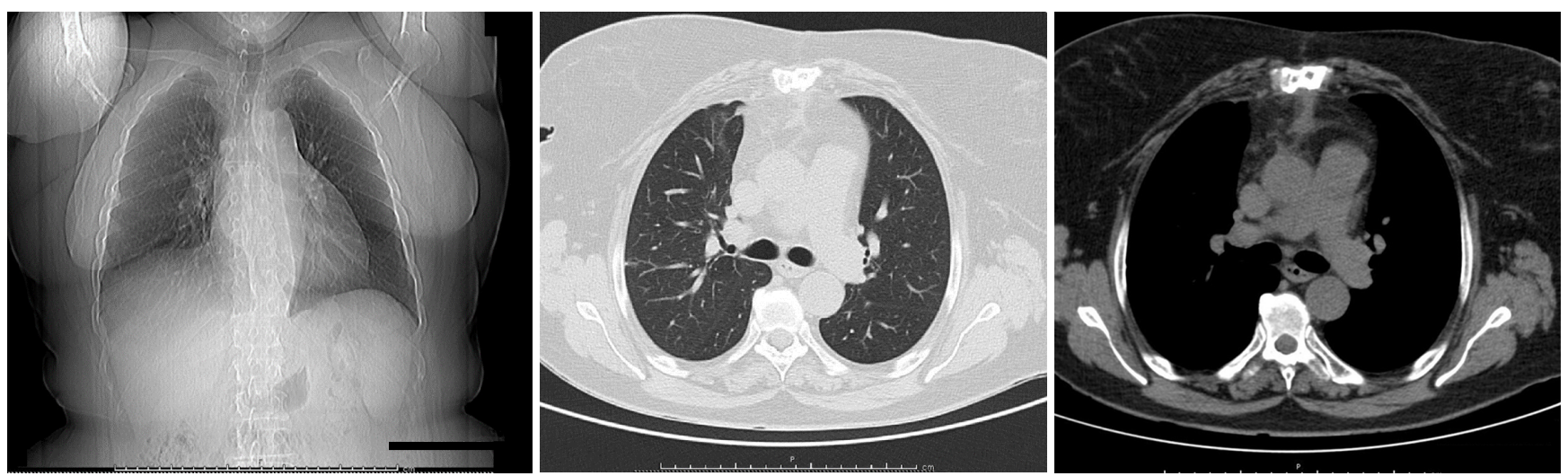

Figure 4 CT scan, first follow up. 
definition of hemangiopericytoma differing from the SFT, representing a rare case of a mediastinal tumour.

Both hemangiopericytoma and SFT are considered "low malignant neoplasm" $(7,8)$.

Considering the size, the site and the $\mathrm{R} 1$ resection in this case, a multidisciplinary group discussion was necessary. The final decision was a radiological follow up.

The first follow-up CT-scan showed no pleural effusion and no sign of recurrence in the mediastinum. At this time patient present an ECOG status 0 (Figure 4).

\section{Conclusions}

Under immunohistochemical, and histological point of view, a hemangiopericytoma is classified as the same tumor as an SFT. SFT is a rare mesenchymal neoplasm, that is usually located at the periphery of the chest or closed to the fissure, with the exclusion of the central areas of the thorax and without involvement of the bone structures.

In the described case we observed different characteristics; a tumour closer to the definition of hemangiopericytoma rather than the one of an SFT, presenting a rare example of a mediastinal tumour.

Subsequently this kind of neoplasms should be taken into account for the differential diagnosis of mediastinal masses with this aspect; in order to guarantee a proper and safe surgical approach.

\section{Acknowledgments}

Funding: None.

\section{Footnote}

Provenance and Peer Review: This article was commissioned by the Guest Editors (Francesco Zaraca, Luca Bertolaccini, Reinhold Perkmann and Roberto Crisci) for the series "Thoracic surgery without borders" published in Current Challenges in Thoracic Surgery. The article has undergone external peer review.

Reporting Checklist: The authors have completed the CARE reporting checklist. Available at https://ccts.amegroups. com/article/view/10.21037/ccts.2020.01.05/rc

Conflicts of Interest: All authors have completed the ICMJE uniform disclosure form (available at https://ccts. amegroups.com/article/view/10.21037/ccts.2020.01.05/ coif). The series "Thoracic surgery without borders" was commissioned by the editorial office without any funding or sponsorship. The authors have no other conflicts of interest to declare.

Ethical Statement: The authors are accountable for all aspects of the work in ensuring that questions related to the accuracy or integrity of any part of the work are appropriately investigated and resolved. All procedures performed in this study were in accordance with the ethical standards of the institutional and national research committees and with the Helsinki Declaration (as revised in 2013). Written informed consent was obtained from the patient for publication of this case report and any accompanying images. A copy of the written consent is available for review by the editorial office of this journal.

Open Access Statement: This is an Open Access article distributed in accordance with the Creative Commons Attribution-NonCommercial-NoDerivs 4.0 International License (CC BY-NC-ND 4.0), which permits the noncommercial replication and distribution of the article with the strict proviso that no changes or edits are made and the original work is properly cited (including links to both the formal publication through the relevant DOI and the license). See: https://creativecommons.org/licenses/by-nc-nd/4.0/.

\section{References}

1. Kouki HS, Koletsis EN, Zolota V, et al. Solitary fibrous tumor of the lung. Gen Thorac Cardiovasc Surg 2008;56:249-51.

2. Shama S, Eshupuniyani P, Bhushan K, et al. Giant solitary fibrous tumor: a rare case report. South Asian J Cancer 2019;8:17.

3. England DM, Hchholzer L, McCarthy MJ. Localized benign and malignant fibrous tumors of the pleura. A clinical pathologic review of 223 cases. Am J Surg Pathol 1989;13:640-58.

4. Park MS, Araujo DM. New insights into the hemangiopericytoma/solitary fibrous tumor spectrum of tumors. Curr Opin Oncol 2009;21:327-31.

5. Wiss SW, Goldblum JR. In: Goldblum J, Weiss S, Folpe AL. et al. editors. Enzinger and Weiss's Soft Tissue Tumor. Saunders 2008:1093-160.

6. van de Rijin M, Lombard CM, Roue RV. Expression of CD34 by solitary fibrous tumors of the pleura, mediastinum, and lung. Am J Surg Pathol 
1994;18:814-20.

7. Cardillo G, Facciolo F, Cavazzana AO, et al. Localized solitary fibrous tumor of the pleura: an analysis of 55

doi: $10.21037 /$ ccts.2020.01.05

Cite this article as: Ceccarelli I, Korasidis S, Sicolo E, Nesti A, Ambrogi MC, Paladini P, Lucchi M. Mediastinal tumour with rare histology: case report. Curr Chall Thorac Surg 202 1;3:9. patients. Ann Thorac Surg 2000;70:1808-12.

8. John D. Mitchell Solitary Fibrous Tumor of the pleura. Elsevier Inc., 2003. 